San Jose State University

SJSU ScholarWorks

Master's Theses

Master's Theses and Graduate Research

Summer 2015

\title{
Frequency of Counseling Sessions and Weight Loss Maintenance in a Commercial Lifestyle-Based Weight Management Program
}

Ashlee K. Jenson Gossard

San Jose State University

Follow this and additional works at: https://scholarworks.sjsu.edu/etd_theses

\section{Recommended Citation}

Jenson Gossard, Ashlee K., "Frequency of Counseling Sessions and Weight Loss Maintenance in a Commercial Lifestyle-Based Weight Management Program" (2015). Master's Theses. 4591.

DOI: https://doi.org/10.31979/etd.vkd5-n73r

https://scholarworks.sjsu.edu/etd_theses/4591

This Thesis is brought to you for free and open access by the Master's Theses and Graduate Research at SJSU ScholarWorks. It has been accepted for inclusion in Master's Theses by an authorized administrator of SJSU ScholarWorks. For more information, please contact scholarworks@sjsu.edu. 
FREQUENCY OF COUNSELING SESSIONS AND WEIGHT LOSS MAINTENANCE IN A COMMERCIAL LIFESTYLE-BASED WEIGHT MANAGEMENT PROGRAM

\author{
A Thesis \\ Presented to \\ The Faculty of the Department of Nutrition, Food Science and Packaging \\ San José State University \\ In Partial Fulfillment \\ of the Requirements for the Degree \\ Master of Science
}

by

Ashlee K. Jenson Gossard

August 2015 
(C) 2015

Ashlee K. Jenson Gossard

ALL RIGHTS RESERVED 
The Designated Thesis Committee Approves the Thesis Titled

FREQUENCY OF COUNSELING SESSIONS AND WEIGHT LOSS MAINTENANCE IN A COMMERCIAL LIFESTYLE-BASED WEIGHT MANAGEMENT PROGRAM

by

Ashlee K. Jenson Gossard

APPROVED FOR THE DEPARTMENT OF NUTRITION, FOOD SCIENCE, AND

PACKAGING

SAN JOSÉ STATE UNIVERSITY

August 2015

Clarie B. Hollenbeck, PhD

Department of Nutrition, Food Science \& Packaging, San José State University

Elizabeth Brown, MS, RD, CSSC Department of Nutrition, Food Science \& Packaging, San José State University

Lesley Lutes, $\mathrm{PhD}$

Department of Psychology, University of British Columbia 


\begin{abstract}
FREQUENCY OF COUNSELING SESSIONS AND WEIGHT LOSS MAINTENANCE IN A COMMERCIAL LIFESTYLE-BASED WEIGHT MANAGEMENT PROGRAM
\end{abstract}

\author{
by Ashlee K. Jenson Gossard
}

Widespread overweight and obesity persist in the United States, and while many effective methods of weight loss have been developed, long-term weight loss maintenance (WLM) remains a challenge. Evidence strongly indicates that ongoing personalized support can effectively promote sustained WLM; however, the optimal frequency of supportive contact has yet to be investigated. This study retrospectively analyzed clinical records from a commercial lifestyle-based weight management program offering personalized WLM counseling. The unique element of this program was participants' ability to select how often to contact their WLM counselor. Following weight loss, participants enrolled in the program's 12-month weight maintenance phase. The question under investigation was whether there was an association between frequency of counseling sessions during maintenance and participants' overall WLM success. After 12 months, participants who completed the program successfully sustained an average $11 \%$ net weight loss. However, no significant relationship was observed between total number of counseling sessions and percent body weight change during maintenance, indicating that other factors may play a role in participant decisions about when to contact their counselor and in their ability to sustain lost weight. Additional research is warranted in the areas of contact frequency, reasons for attrition, and additional factors mediating counseling support and WLM. 


\section{ACKNOWLEDGEMENTS}

The pursuit and completion of this project and this program would never have been possible without the support of many important people. First and foremost, my deepest appreciation goes to my SJSU committee, Clarie Hollenbeck and Izzie Brown, for their thoughtful critiques, generous donations of time, and ongoing assistance with helping me find just the right words with which to speak my ideas; and to Lesley Lutes, for inspiring me toward studying nutrition in the first place, and graciously returning a decade later to help me complete that journey. My gratitude also goes to the rest of the Nutrition, Food Science \& Packaging Department faculty and staff at SJSU, who have provided incredible support and encouragement throughout my studies. Many thanks to Jennifer Lesyna and Linda Hicks for their cooperation in this project, and to Lily Kimbel and Abby Jenson for so charitably helping with data collection. Finally, this would never have been possible without the overwhelming support of my entire family, especially my husband Neal, whose unwavering faith in me has helped lift me up and keep me going for many years. 


\section{TABLE OF CONTENTS}

Page

List of Tables

viii

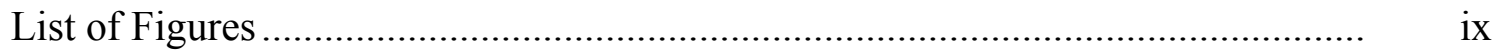

CHAPTER 1: Introduction and Literature Review.......................................... 1

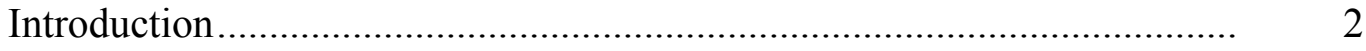

Review of the Literature ..................................................................

Weight Management Counseling in Healthcare .......................... 3

Program Approaches to Weight Loss ....................................... 4

Long Term Weight Loss Maintenance ..................................... 6

Challenges of Sustaining Lost Weight.............................. 6

Motivation for Weight Loss Maintenance ....................... 7

Effects of Dietary Weight Loss Approaches on Long- 8

Term Weight Loss Maintenance

Successful Weight Loss Maintenance Behaviors: The

National Weight Control Registry

Program Approaches to Weight Loss Maintenance

Remote Contact Via Technology

Remote vs. In-Person Support

Frequency of Contact.

Summary \& Objective

CHAPTER 2: Journal Article

Abstract 


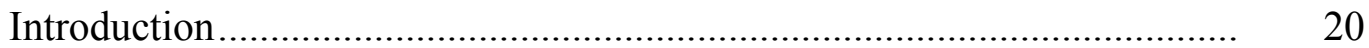

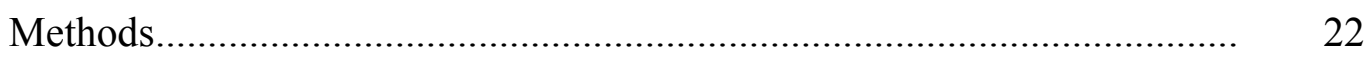

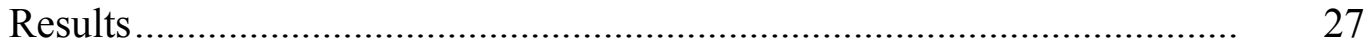

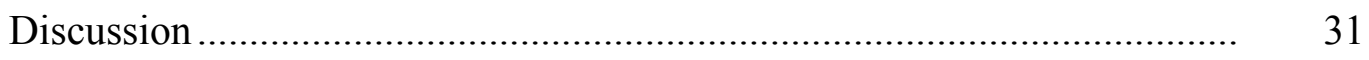

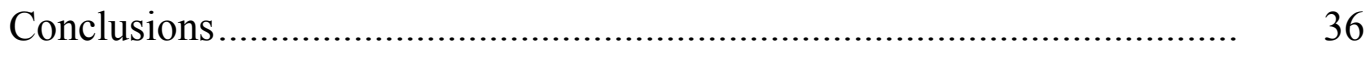

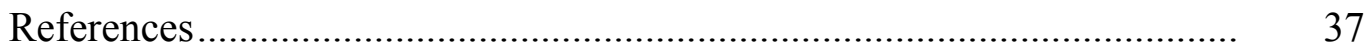

CHAPTER 3: Summary and Recommendations ................................................... 41

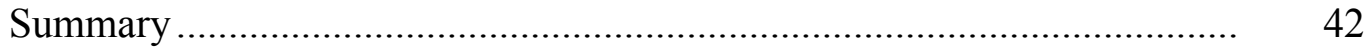

Recommendations................................................................................. 43

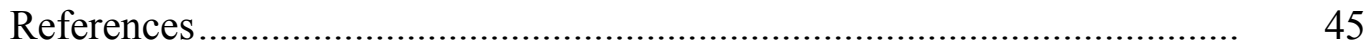

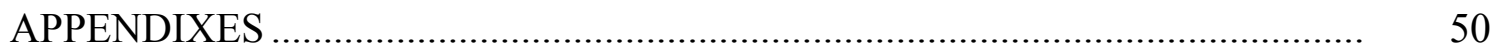

A. Letters of Consent from Participating Facilities …………………......... 51

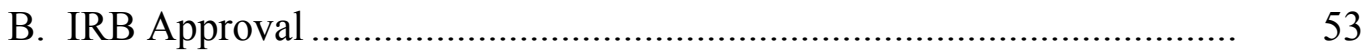




\section{LIST OF TABLES}

Page

Table 1. Quartile Classification Criteria for Weight Change and Counseling

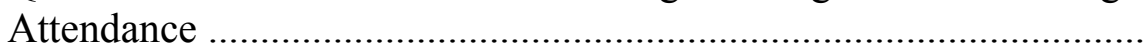

Table 2. Sample Demographics, Weight Change, and Counseling Session Attendance.

Table 3. Participant Quartile Distribution for Counseling Session Attendance and Weight Change .......................................................... 


\section{LIST OF FIGURES}

Page

Figure 1. Percent Weight Change vs. Number of Counseling Sessions Attended During Weight Loss Maintenance................................. 
CHAPTER 1

INTRODUCTION AND REVIEW OF THE LITERATURE 


\section{Introduction}

Overweight and obesity remain widespread in the United States, despite increasing attention in research and public policy. According to the Centers for Disease Control and Prevention (CDC), in 2012 over two-thirds (69.0\%) of U.S. adults were overweight, with roughly half of those (34.9\% of all US adults) classified as obese (CDC, 2013). Overweight is defined as having a body mass index (BMI) of $25-29.9 \mathrm{~kg} / \mathrm{m}^{2}$, while a BMI $>30.0 \mathrm{~kg} / \mathrm{m}^{2}$ meets the definition of obese (CDC, 2014a). Increasing rates of overweight and obesity have been strongly linked to the rise in chronic and lifethreatening diseases such as type 2 diabetes, cardiovascular diseases, stroke, some types of cancer, chronic respiratory diseases, renal diseases, and premature mortality (CDC, 2014b; de Mutsert, Sun, Willett, Hu, \& van Dam, 2014; Nawaz \& Katz, 2001). Annual medical costs associated with the treatment of obesity-related diseases were estimated at $\$ 147$ billion in 2008 and have continued to rise in recent years (CDC, 2014b).

In an effort to counter these alarming trends, a wide range of approaches to weight loss have been developed in recent decades, and many have been found effective at inducing substantial initial weight loss (Jensen et al., 2014). However, sustaining the losses long-term remains difficult; the vast majority of individuals eventually regain a significant portion of the lost weight (Anderson, Konz, Fredrich \& Wood, 2001; Perri, 2014; Powell, Calvin III, \& Calvin Jr., 2007). In addition, rates of weight loss and the ability to sustain a loss tend to decline with each subsequent weight loss attempt, further complicating weight loss maintenance (WLM) (Myers et al., 2013). 
Awareness of these challenges has inspired abundant WLM research in recent decades. Successful WLM behaviors, attitudes, and strategies have become progressively understood, and the most effective modes of intervention in order to promote long-term WLM are being gradually clarified (American Dietetic Association [ADA], 2008; Jensen et al., 2014; Thomas \& Wing, 2009).

Research indicates that ongoing support is usually necessary for continued WLM; however, the optimal frequency, intensity, and mode of communication (e.g. in-person, telephone, technology-based, mail) for WLM treatments remain under investigation (Dale et al., 2009; Pinto et al., 2008; Powell et al., 2007; Sherwood et al., 2013; Svetkey et al., 2008; Tang, Abraham, Greaves, \& Yates, 2014; Thomas, Vydelingum, \& Lawrence, 2010; Wing, Tate, Gorin, Raynor, \& Fava, 2006). One feature such studies have in common, however, is that the frequency of contact with the participants is predetermined by the research design, offering little or no freedom for participants or investigators to alter the frequency or method of contact in response to changes in a participant's needs over time.

\section{Review of the Literature}

\section{Weight Management Counseling in Healthcare}

Despite the association between obesity and health conditions, patients at risk for or suffering from chronic disease now receive less nutrition and weight management counseling from their physicians than they did 20 years ago (Kraschnewski et al., 2013). This is troublesome given evidence that being warned by a physician of a weight-related health concern is strongly associated with improved weight management (Greenwood, 
2009; Klem, Wing, McGuire, Seagle, \& Hill, 1997; Wing \& Phelan, 2005). Furthermore, many insurance plans currently limit coverage for consulting a registered dietitian (RD) or other nutrition professional to those patients with severe medical diagnoses, such as heart failure or kidney disease (Academy of Nutrition and Dietetics [AND], 2013; United Healthcare, 2014). Due to this lack of support from the healthcare system, many people interested in weight management must turn to the private sector for support and dietary advice.

\section{Program Approaches to Weight Loss}

Weight loss programs are highly varied in the strategies they employ to induce weight loss. For example, dietary interventions may restrict overall caloric intake, manipulate the distribution of macronutrients (protein, carbohydrate, and fat), or identify certain food groups or types of food to be emphasized or avoided (Anderson, Vichitbandra, Qian, \& Kryscio, 1999; Brantley et al., 2008; Brunerova, Smejkalova, Potockova, \& Andel, 2007; Dale et al., 2009; Ebbeling et al., 2012; Johansson, Neovius \& Hemmingsson, 2013; Maki, Rains, Kaden, Raneri, \& Davidson, 2007). Dieters may be instructed to shop for their own food within certain guidelines, purchase a program's prepackaged meals, replace meals with liquid supplements and/or nutrient bars, or some combination thereof (Anderson et al., 1999; Ashley, St. Jeor, Perumean-Chaney, Schrage, \& Bovee, 2001; Brantley et al., 2008). Medical approaches such as pharmaceuticals or bariatric surgeries, often coupled with diet and exercise, can also induce weight loss (Desouza et al., 2012; Powell et al., 2007). Finally, physical activity recommendations ranging from moderate to extremely intensive exercise are frequently included as part of 
many weight loss programs (Kouvelioti, Vagenas \& Langley-Evans, 2014; Nawaz \& Katz, 2001).

Weight loss program material may be disseminated via various modalities. Selfdirected programs are independently utilized by participants at their own discretion via a website or printed materials, typically without personalized contact with an interventionist (Tang et al., 2014; Thomas et al., 2010). In contrast, personalized programs provide individualized feedback and direct interaction between the participant and the interventionist, with contact methods ranging from in-person group or individual sessions to technology-based communication via phone, text-message, or email (Dale et al., 2009; Desouza et al., 2012; Nguyen et al., 2013; Perri et al., 2008; Sherwood et al., 2013; Svetkey et al., 2008; Wing et al., 2006).

The consensus from several health professional groups such as the American College of Cardiology, American Heart Association and The Obesity Society is that all of the approaches listed above have the capacity to produce substantial weight loss in the short-term (Jensen et al., 2014). Evidence suggests that a 3-5\% reduction of initial body weight can reduce several chronic disease risk factors, such as high blood pressure, elevated blood glucose, high abdominal adiposity or large waist-hip ratio (Powell et al., 2007). Because larger losses can produce greater reductions in risk, a "clinically significant" weight loss target is typically set at $5 \%$ or $10 \%$ of initial body weight (Jensen et al., 2014). However, in order to maximize the health benefits of weight loss, the lost weight must not be regained (Nawaz \& Katz, 2001); therefore, the real challenge of any diet plan is to produce clinically significant, sustainable weight loss. 


\section{Long-Term Weight Loss Maintenance}

Despite the wide range of approaches to weight loss, weight regain is consistently a significant problem (ADA, 2008; Kouvelioti et al., 2014; Nawaz \& Katz, 2001; Orleans, 2000). WLM rates, across all methods of loss and regardless of the amount of weight lost, have been reported to average only $3 \%$ total body weight after 5 years (Anderson et al., 2001); less than $30 \%$ of individuals manage to sustain a loss of $\geq 10 \%$ body weight for 3 years, a rate which drops to 25\% after 5 years (Anderson et al., 1999). The Look AHEAD trial, which provided intensive and comprehensive lifestyle modification support for weight loss among Type 2 Diabetes patients, was one of the few known studies demonstrating meaningful long-term weight loss success rates, with a majority of participants sustaining at least 5\% weight loss after 8 years (Perri, 2014).

Challenges of sustaining lost weight. The reasons for weight regain are numerous and varied. Orleans (2000) argued that many weight loss programs deliberately create an isolated environment in terms of food utilization, access, and support that is tailored to strengthen the chances of weight loss. However, upon release from the program, participants often find that the outside world is not similarly designed to support behaviors necessary for WLM: elements such as abundant food advertising, ready availability of low-cost calorie-dense foods, and a built environment which limits daily physical activity reflect a society and culture which seem to embrace comfort and indulgence over health and dietary restraint. Given the disparity of message, support, and food accessibility between the weight loss program and the participant's external environment, it should not be surprising that people tend to regain their weight. 
Alterations to metabolic processes and to the gut microbiome as a result of weight loss are also being explored for their contributions to weight regain (Ebbeling et al., 2012; Sweeney \& Morton, 2013).

Motivation for weight loss maintenance. WLM has historically been viewed as a "final destination" after weight loss, the endpoint of a path; recently, however, researchers are beginning to see weight management as a cycle of restraint and relapse, a journey toward sustained WLM that requires constant motivation and extended therapeutic support (Orleans, 2000). Teixeira, Silva, Mata, Palmeira, \& Markland (2012) noted that the motivation to lose weight seems distinctly different from the motivation to maintain one's weight. The novelty and benefits of losing weight, such as positive comments from peers, aesthetic improvements, and decreasing weight numbers on the scale, may be adequately motivating to keep most individuals focused during weight loss. However, these external benefits tend to wane during extended WLM and become insufficiently rewarding to impel people to continue their WLM behaviors. It was suggested that the best way to sustain behavior change is through the development of fully internalized motivation, defined and developed by each individual, which focuses on one's self-concept as a thinner individual and the benefits of being at - rather than striving towards - a lower weight (Teixeira et al., 2012). To support this long-term motivational shift, ongoing, highly individualized counseling throughout WLM is strongly encouraged, although the most effective WLM treatment methods require further clarification (Orleans, 2000; Powell et al., 2007; Teixeira et al., 2012). 


\section{Effects of dietary weight loss approaches on long-term weight loss}

maintenance. In an effort to stem weight regain, some investigators have explored whether any of the dietary approaches to weight loss described above exhibit differential benefits for long-term WLM. Conventional recommendations from nutrition professionals for the most sustainable weight loss promote moderate caloric restriction, high intakes of fruits, vegetables, fiber, whole grains, lean meats and protein sources, and limited intake of highly processed, high calorie foods of low nutrient density; these diets typically consist of a balanced macronutrient profile similar to the recommendations for all healthy adults (ADA, 2008). Alternative dietary patterns, such as low carbohydrate or low glycemic index diets, have shown mixed WLM results (Ebbeling et al., 2012; Maki et al., 2007). Evidence regarding programs that rely upon artificial nutrition (e.g. very low calorie diets with liquid supplements, diet plans using complete meal replacements, and/or anti-obesity drugs) in the initial phases of WLM indicates that once the supplementation, meal replacements, and/or drugs are terminated, only those groups who use conventionally available foods, behavioral strategies and lifestyle modification maintain clinically significant losses over time (Johansson et al., 2013; Pinto et al., 2008; Powell et al., 2007). It has been suggested that these participants may experience improved confidence, greater self-efficacy, and stronger WLM skills as a result of losing weight on their own, whereas the participants who lost weight using artificial methods may be less well prepared for managing their diets without these aids (Pinto et al., 2008).

In summary, regardless of the method used to lose weight, individuals seeking WLM must be prepared to moderate their intake indefinitely, using food available in 
everyday life. The ADA similarly concluded in their position paper on Weight Management that "successful weight management to improve overall health for adults requires a lifelong commitment to healthful lifestyle behaviors emphasizing sustainable and enjoyable eating practices and daily physical activity" (ADA, 2008, p.1).

\section{Successful weight loss maintenance behaviors: The National Weight Control}

Registry. The specific weight management methods of successful maintainers have historically been difficult to track. The majority of information regarding successful WLM behaviors is derived from the National Weight Control Registry (NWCR), a large, prospective study established by Hill \& Wing in 1994 (NWCR, n.d.). The NWCR is a database of several thousand individuals who have maintained a loss of at least $30 \mathrm{lbs}$ or $10 \%$ of their maximum body weight for at least one year. Surveys of personal, psychological, and behavioral characteristics are sent to each registrant annually, allowing the identification of factors associated with weight gain, weight loss strategies previously employed, and strategies currently employed in their WLM efforts.

The information derived from NWCR has generated 31 publications since its initiation (http://www.nwcr.ws), contributing heavily to the body of knowledge available regarding successful WLM. Wing and Phelan (2005) provided an excellent summary of these findings, which have remained consistent over the registry's two-decade history. Approximately half of participants lost weight through structured programs, whereas the rest lost the weight on their own. The vast majority (94\%) of registrants successfully sustaining their lost weight used a combination of diet and exercise during both weight loss and WLM. The most commonly endorsed dietary strategies were similar to 
conventional recommendations, average caloric intake was well below expected caloric needs, and frequent exercise was an integral component of WLM. Registrants also reported consumption of a highly consistent diet from day to day, a high level of cognitive restraint in eating behaviors, regular dietary self-monitoring, and frequent selfweighing to monitor their weight status and adjust their dietary intake or exercise accordingly (Wing \& Phelan, 2005). These behaviors represented a distinct departure from most registrants' described lifestyles prior to losing their weight, and indicated that successful WLM requires significant, sustained effort and commitment to a major lifestyle change (Klem et al., 1997).

\section{Program Approaches to Weight Loss Maintenance}

Knowing the behaviors and strategies that promote successful WLM is a critical first step. Next, the most effective methods of delivering this information to participants to facilitate sustained behavior change must be determined. The same contact options used in weight loss programs have been explored in WLM, ranging from self-directed and/or strictly technology-based modalities to personalized contact by telephone or email and individual or group in-person sessions with a trained health professional. Contact frequency typically ranges from biweekly to quarterly, and duration of support may vary widely from less than 6 months to several years (Ashley et al., 2001; Perri et al., 2008; Sherwood et al., 2013; Tang et al., 2014). Most long term WLM programs follow participants for 12, 24, or 36 months after weight loss; few have traced maintenance patterns for at least 5 years (Anderson et al., 2001; Maki et al., 2007; Perri, 2014; Radcliff et al., 2012; Sherwood et al., 2013; Svetkey et al., 2008; Thomas et al., 2010; 
Wing et al., 2006). Fortunately, the greatest weight regain typically occurs within the first few years after loss, and the longer an individual's weight loss is maintained, the less likely they are to regain weight in the future (Anderson et al., 1999; Wing \& Phelan, 2005).

Remote contact via technology. Given the high demand for resources required by a long-term program, some programs exclusively contact participants remotely via email, telephone, or text message, and have shown some success. For example, Thomas et al. (2010) found that after 6 months of WLM following weight losses of 10-11\% initial body weight, participants who were emailed weekly WLM tips regained significantly less (1.2\%) of that lost weight compared with a no-contact control group (3\% regain). A longer trial by Sherwood et al. (2011) provided 24 months of phone-based individual WLM counseling sessions tapering from biweekly to bimonthly for participants who had lost $\sim 16 \%$ initial body weight. Adherence to WLM behaviors and overall health outcomes were significantly improved in the phone-based guided-support condition compared with self-guided controls who received only a printed booklet (3.2\% regain vs. $5.1 \%$ regain for controls). This program was also unique in that it was one of the only programs allowing for any type of contingent care: if a phone-support participant's weight trended up more than 2 lbs over 4 weeks, an additional outreach call was conducted in an effort to help the individual reverse the weight regain (Sherwood et al., 2011). No discussion of the utilization or benefits of contingency phone calls were provided (Sherwood et al., 2013). 
Remote vs. in-person support. Two additional large-scale randomized trials compared monthly in-person group support, monthly interactive web-based support, and controls who received printed materials only. One study (Wing et al., 2006) found that in-person contact facilitated the most consistent participant attendance and least weight regain after 18 months $(2.5 \%$ initial body weight $)$, with the internet program and mailbased controls regaining the most weight $(4.8 \%$ and $5.1 \%$ regain, respectively; Wing et al., 2006). A second study (Svetkey et al., 2008) similarly found that following a mean weight loss of $8.5 \%$ body weight, the in-person support group demonstrated the smallest regains in weight (4.1\% initial body weight) over 30 months; the online-only intervention also showed no improvement in WLM over self-directed controls who received only printed recommendations at the start of the program $(5.3 \%$ vs. $5.7 \%$ regain, respectively; Svetkey et al., 2008).

Perri et al. (2008) provided more frequent contact during a WLM program following a 6 month in-person group weight loss program. In-person biweekly group WLM support sessions were compared with individual biweekly phone-based counseling and mail-based controls; after 12 months, both treatment groups showed significantly improved WLM compared with controls. However, the design of this study did not allow separate analyses for individual vs. group treatments and in-person vs. phone-based contact, which raises the question of whether the degree of personalization (individual vs. group) or mode of contact (in person vs. phone) is more contributory to WLM success; nor was contact frequency manipulated within treatment arms. Interestingly, the phonebased support, which was designed as an attempt to provide lower-cost weight 
management counseling in rural areas with limited public funding, was only found to be more cost effective than in-person counseling (in terms of cost per pound sustained) when the in-person group sizes were much larger than is typical for most group-based programs (16-20 people, vs. 8-10 in most programs; Radcliff et al., 2012).

Frequency of contact. While methods of contact have received ample attention in the available WLM literature, little research to date has specifically isolated the question of contact frequency in WLM. Counselors providing more frequent treatment may be able to respond rapidly to shifts in participants' motivation, redirect apathy, and prevent small relapses from turning into major weight regain (Desouza et al., 2012; Orleans, 2000; Teixeira et al., 2012). Furthermore, more frequent contact has been proposed to particularly help individuals with higher levels of perceived stress in their lives, who are at greater risk of regain (Cho, Jae, Choo \& Choo, 2014).

In their study of health-related behavior change in overweight teens, Nguyen et al. (2013) combined face-to-face and technology-based strategies by supplementing infrequent (quarterly) in-person sessions with more frequent (biweekly) technology-based contact (text messaging and individual phone calls). It was predicted that teens would better sustain their health- and weight-related behavior changes with more frequent, ongoing technology-based support, but no significant differences were found in sustained behavior change between those who did and did not receive the supplemental contact at the end of 12 and 24 months. It was proposed that the infrequent in-person sessions might have been an inadequate level of support to be overcome by supplemental text- and phone-based contact (Nguyen et al., 2013). 
Recently, Perri et al. (2014) did directly manipulate treatment frequency (“dose”) of supportive contact in their 24 month behavior modification weight management program conducted at university extension offices in rural areas. Greater weight loss was observed in the moderate and higher dose conditions $(6.7 \%$ for 32 sessions and $6.8 \%$ for 48 sessions) compared to lower dose conditions and nutrition education-only controls (3.5\% and $2.9 \%$, respectively). However, this program was focused on weight loss, not WLM, and as has been previously described, participants' needs and behaviors associated with WLM may differ markedly from those for weight loss. Therefore, while more intensive contact may be effective for greater weight loss, the same has not yet been demonstrated for WLM.

In another unique approach to WLM treatment attempting to identify costeffective WLM treatment modalities, Dale et al. (2009) conducted a 24 month in-person WLM program, during which clinical expertise ("intensity") of the counselor was the manipulated factor. Following weight loss, one group of participants received brief weekly consults with a registered nurse and attended monthly group support sessions (low clinical "intensity"); the other group received lengthy in-person consults with a highly trained clinical team consisting of a physician, registered dietitian and exercise physiologist (high "intensity"), in which consults occurred initially every 6 weeks, gradually declining to every 3 months. After 24 months, both groups exhibited similar overall improvements in weight, sustaining net weight reductions of $6.3-6.7 \%$, as well as several biomedical markers for weight-related diseases. The authors concluded that the lower-cost, less clinically intensive nurse-led program adequately supported WLM 
lifestyle changes for improved health compared to the high clinical intensity program, but failed to consider the potential contribution of the more frequent contact provided in the nurse-led group (Dale et al., 2009).

\section{Summary \& Objective}

Current research indicates that modest weight loss can lead to significant improvements in an individual's health status and risk of disease if the lost weight is sustained; however, long-term WLM remains a persistent challenge. The behaviors most strongly associated with successful WLM often require intensive lifestyle modification and appear to be best supported with ongoing interpersonal counseling, which can help individuals problem-solve, recover from relapse, and find a deeper personal meaning in their newly-adopted healthy lifestyle to sustain their motivation. However, ideal frequency of this personal contact in WLM has yet to be determined.

One unaddressed element of research-based approaches to WLM is the necessity of a pre-determined contact protocol. Nearly all the WLM programs described above prescribe a biweekly, monthly or bimonthly follow-up pattern with little or no contingency care available if participants should require additional support. While research-based interventions must endeavor to treat all participants equally in order to evaluate the benefits of a distinct variable being tested, this strict structure may not necessarily reflect the individual's actual needs or preferences for support. Such a design may also fail to access the natural behavior of free-living individuals given a choice about how and when to utilize available services, and may provide support too inadequately in the moments when participants need it most. 
In contrast, commercial WLM programs may not be so restricted in their ability to adapt their services to the individual needs of their customers. The option for more frequent and flexible contact offered by such a program may help participants stay focused and motivated, thereby proactively preventing small weight regain or relapses in behaviors from turning into significant weight regain. By allowing program participants to decide for themselves whether and when they communicate with their weight loss counselor, better insight may be afforded into the needs and preferences of individuals trying to sustain recent weight loss, and the association of these contact patterns with participants' weight changes during the course of the WLM program can be observed. Such information may be critical to the development of more effective WLM programs.

The present study explored the relationship between frequency of counseling support and weight regain in a commercial lifestyle-based weight management program offering personalized weight management counseling, which allowed participants to select how frequently they utilized the counseling services provided. Participants in this study participated in the weight loss phase of the program, reached a weight they were satisfied to maintain, and opted to enroll in the 12-month maintenance phase. The question under investigation was whether there was any association between frequency of participants' visits to the counseling center and their overall success at sustaining their lost weight. Primary outcome measures included weight change over the WLM program relative to initial body weight and the amount of weight lost, and total number of sessions undertaken by each participant during the WLM program. Because more personalized support and increased motivation have been associated with improved WLM (Brantley et 
al., 2008; Coughlin et al., 2013; Jensen et al., 2014; Tang et al., 2014; Teixeira et al., 2012), it was hypothesized that those participants who visited their counselors more often would demonstrate better rates of WLM. 
CHAPTER 2

FREQUENCY OF COUNSELING SESSIONS AND WEIGHT LOSS MAINTENANCE IN A COMMERCIAL LIFESTYLE-BASED WEIGHT MANAGEMENT PROGRAM 


\begin{abstract}
Long-term weight loss maintenance (WLM) following weight loss is a persistent challenge. Personalized WLM counseling is strongly indicated to support WLM behaviors, but ideal frequency of contact remains unclear. This study investigated the association between counseling frequency and weight regain when participants selected their own counseling schedules. This retrospective analysis from a 12-month commercial lifestyle-based weight management program providing drop-in individual counseling sessions examined initial weight loss, WLM weight change, and number of counseling sessions attended. Overweight, primarily middle-aged participants who completed the program lost $11.5 \% \pm 6.8 \%$ initial body weight and regained minimal weight during maintenance $(+0.55 \% \pm 4.9 \%)$. Number of counseling sessions was not significantly associated with WLM $(r=-.134, p=.308)$. Modest associations linked WLM to faster initial weight loss $(r=.275, p=.034)$ and purchasing additional WLM support $(r=-.291$, $p=.024)$. Additional research is warranted to determine ideal contact frequency and other potential mediating variables between personalized support and successful WLM.
\end{abstract}

Keywords: weight loss maintenance, weight management, obesity, counseling, supportive contact 


\section{Introduction}

Overweight and obesity in the United States remain widespread, despite increasing attention in research and public policy (U.S. Centers for Disease Control and Prevention, 2013). A wide range of approaches to weight loss has been found effective at inducing substantial weight loss (Jensen et al, 2014). However, sustaining such losses has remained patently difficult, with the vast majority of individuals regaining some, all, or even more weight than they originally lost (Anderson et al., 2001; Powell et al., 2007).

Most knowledge of successful weight loss maintenance (WLM) behaviors is derived from the National Weight Control Registry, a large database of individuals who have lost and sustained a significant percentage of body weight for at least one year. This registry has identified numerous personal factors, dietary strategies, and behavioral modifications (e.g. dietary intake, exercise, coping strategies, self-monitoring, support mechanisms, etc.) associated with successful WLM (Thomas \& Wing, 2009; Wing \& Phelan, 2005). Many WLM interventions have attempted to teach such behavioral modification and coping strategies to participants, exploring various program formats and methods of communication to determine the factors of support most conducive to longterm WLM. There is strong evidence that successful WLM is best supported with ongoing individualized counseling (Dale et al., 2009; Desouza et al., 2012; Nguyen et al., 2013; Perri et al., 2008; Perri et al., 2014; Sherwood et al., 2013; Svetkey et al., 2008; Wing et al., 2006). Orleans (2000) and Teixeira et al. (2012) suggested that continued personalized support throughout WLM may promote long-term motivational shifts, help individuals problem-solve, and promptly reverse short periods of relapse. 
However, frequency of personal contact during WLM has been insufficiently isolated in any of the published literature available. In their study on the pharmaceutical treatment of apathy and in-person counseling during weight loss, Desouza et al. (2012) briefly mention that the number of sessions per week was the strongest predictor of weight loss, but this outcome is not discussed further. Perri et al. (2014) also found that during weight loss, more contact was associated with greater weight reduction; however, these same associations have not been explored in WLM, during which participants' needs may differ from during weight loss (Teixeira et al., 2012). No WLM studies reviewed addressed contact frequency directly, and all adhered to a pre-determined follow-up schedule. Sherwood et al. (2013) provided phone-based individual WLM counseling on a biweekly schedule and did allow brief increased contact if a participant's weight was trending up, but the effect of this increased contact was not assessed.

Allowing participants to decide whether and when they contact their WLM counselor may afford better insight into the needs and preferences of individuals trying to sustain recent weight loss. The present study explores a commercial lifestyle-based WLM program offering personalized counseling which allowed participants to select how often they utilized the counseling services offered. The question under investigation is whether there is an association between frequency of participants' sessions to the counseling center during the 12-month WLM program and their overall WLM success. Because more personalized support has been associated with improved WLM, it is hypothesized that those participants who visited counselors more often would demonstrate more successful WLM. 


\section{Methods}

\section{Study Design}

The present study is a retrospective examination of pre-existing clinical records to investigate the relationship between participants' attendance at a WLM counseling center and total weight change over the 12-month WLM program, following participation in the weight loss program.

\section{Participants}

The records of 199 adults who purchased a 12-month WLM program from a commercial weight loss consulting franchise in the San Francisco Bay Area during the years 2004-2013 were reviewed for this study. All participants had previously completed the company's weight loss program and reached a weight they were satisfied to maintain before being allowed to enroll in the WLM program. Because of the commercial nature of this study, available demographic information was limited to gender, year of birth, height, and weight. Exclusion criteria were current chemotherapy treatment and/or cancer diagnosis, pregnancy or breastfeeding, and age $<18$ years.

\section{Diet Program}

The diet plans for weight loss and WLM were very similar, with the purpose of establishing healthy eating habits during weight loss that would be sustained indefinitely for WLM. The program directed participants toward conventionally available foods low in fat, sugar, and sodium; moderate carbohydrate restriction and adherence to foods designated low glycemic index; and high intake of fresh fruits and vegetables, lean meats, and low-fat or fat-free dairy products. Behavioral modifications included portion control, 
consumption of small frequent meals, daily food tracking and meal planning, frequent (daily or weekly) self-weighing, and regular moderate physical activity.

All sessions with a counselor were held individually and conducted on a drop-in, ad libitum basis. During the weight loss phase, participants were allowed unlimited access to the center; at least 2-3 sessions per week was recommended, but some participants chose to visit daily and others once per week or less. Following the weight loss phase, participants opted to enroll in the 12-month (repeatable) WLM phase, during which weekly sessions were encouraged although participants were allowed to visit more or less often if they desired. Phone or email consults were also available if the participant was unable to attend in person.

During counseling sessions, the participant's weight was recorded and food logs were reviewed to ensure dietary targets were being met. While the basic diet plan remained similar between the weight loss and WLM phases, WLM sessions focused on incorporating a greater diversity of foods into the diet and gradually increasing portion sizes to stabilize weight. Participants also discussed with their counselor recent challenging and/or successful experiences, behavioral relapses, motivational issues, problem-solving and long-term goal-setting.

\section{Data Collection \& Measurements}

A manual review was conducted of all client files from 2004-2013 available from five different franchise sites in the region. In this completers-only analysis, files were included for analysis only if the client enrolled in the 12-month WLM program, attended at least 5 sessions, and the final session occurred within 30 days of the scheduled end 
date (participants completed at least 11 months of the program). The purpose of this type of analysis was to establish a common duration of treatment (11-12 months) for all included participants, while allowing each participant's attendance frequency within that timeframe to vary naturally. Records were randomly assigned a 3-digit identification number to maintain client anonymity.

Weight loss. Participants determined the duration of their weight loss phase based on their desired amount of weight loss, progress, and willingness to continue trying to lose weight or readiness to maintain their current weight; programs lasted a minimum of 6 weeks and could be renewed or extended indefinitely. Accordingly, to assess total initial weight loss and duration of weight loss phase (the elapsed time prior to the participant declaring intent to maintain their current weight) the first and last dates of all weight loss counseling sessions and the participant's weight at these sessions were recorded. Goal body mass index (BMI), the BMI each participant indicated they would like to maintain regardless of whether they had actually reached this BMI prior to WLM, was also recorded.

Weight maintenance. The first day of the 12-month WLM program was defined as the first date the participant attended the center after signing the WLM program contract and had their weight recorded; the last day was defined as 365 days later. Every occasion in which there was contact with the participant and a weight was recorded was considered a session, and the total number of sessions was tabulated. The majority of sessions took place in person and the weights were obtained on the centers' medicalgrade scales; however, on some occasions, sessions were held remotely (via email or over 
the telephone), and the weight was self-reported by the participant. For the purposes of this study, self-reported weights and remote sessions were not distinguished from inperson sessions.

Continued support. For any participant who opted to continue receiving WLM support for a second year, the last known weight and date of attendance during the second WLM program were recorded as a measure of long-term weight change with ongoing WLM support. Participants could also engage in more than one cycle of weight loss and WLM, returning to the counseling center for additional weight loss/WLM services at some point after the initial programs were completed (usually after regaining weight). For these individuals, only the first weight loss/maintenance cycle was included for analysis; however, their weight on the first day they returned to the center following the end of their WLM program was also included in the data set, as an indicator of long-term weight change following termination of WLM support.

\section{Statistical Analyses}

All data was analyzed using SPSS ${ }^{\circledR}$ v.22.0 using a "completers-only" analytical approach. Descriptive statistics (mean, range, standard deviation) for participants who completed at least 11 months of the 12-month program were calculated for age, gender, initial BMI, percent of initial body weight lost, percent of initial body weight change during WLM, and number of WLM sessions. Continuous variables were assessed by Pearson's correlation, discrete variables by $\chi^{2}$ and Spearman's rho, and statistical significance was set at $\mathrm{p}<.05$. 
Primary outcome. The primary comparison of interest was WLM weight change and number of sessions attended. WLM weight change was calculated as a percentage relative to initial body weight; for example, a person weighing $200 \mathrm{lbs}$ who lost $20 \mathrm{lbs}$ (10\%) during weight loss and regained $10 \mathrm{lbs}$ during WLM would represent $+5 \%$ WLM weight change. The data for each of these variables were also grouped into quartiles defined by criteria representing meaningful strata of WLM outcomes. The criterion and indication for each quartile is listed in Table 1. Organizing participants into these quartiles was intended to allow detailed insight into associations between session frequency and weight change. For example, it was plausible that those who checked in more frequently might represent both those participants who were most successfully maintaining their weight and those who were struggling most.

Table 1

Quartile Classification Criteria for Weight Change and Counseling Attendance

\begin{tabular}{|lcll|}
\hline Outcome & Quartile & Criteria & Indication \\
\hline \multirow{3}{*}{ Attendance } & 1 & $\geq 48$ sessions & On average, once or more weekly \\
& 2 & $36-47$ sessions & On average, once every 10 days \\
& 3 & $20-35$ sessions & On average, every other week \\
& 4 & $<20$ sessions & On average, less than twice monthly \\
WLM & 1 & $\geq-5 \%$ & Significant continued weight loss \\
Weight & 2 & $-0.1 \%-<-5 \%$ & Modest continued weight loss \\
Change & 3 & $+0.1 \%-<+5 \%$ & Modest weight regain \\
& 4 & $\geq+5 \%$ & Significant weight regain \\
\hline
\end{tabular}


Secondary outcomes. Rate of weight loss was calculated by dividing the total percent body weight lost by the total number of elapsed days (from the first date the participant began the weight loss program to their last session prior to initiating WLM). One set of secondary outcomes analyzed associations between weight loss characteristics (i.e. initial BMI, rate of weight loss, and length of weight loss period), WLM weight change, and WLM attendance. A second set of secondary outcomes analyzed associations between these weight loss or WLM characteristics and the participant's decision to seek additional support at a later date (i.e. enroll in a second WLM program contiguously, or return later seeking additional weight loss).

\section{Results}

\section{Participants}

Of the 199 WLM records available, 60 records fit the required inclusion criteria described above; this represents $70 \%$ attrition. Table 2 summarizes the sample demographics, WLM weight change outcomes, and WLM attendance for the 60 participants who completed the program.

Participants were primarily female, middle-aged (mean $53.2 \pm 9.7$ years), and overweight (mean BMI $=28.4 \pm 4.3$ ) prior to initiating weight loss. During the weight loss program, participants lost a substantial amount of weight (mean $-20.2 \pm 14.4 \mathrm{lbs}$, or $-11.5 \% \pm 6.8 \%$ of initial body weight) over an average of 6 months, with $87 \%$ achieving clinically significant weight loss of $\geq 5 \%$. During the 12 -month WLM period, average weight change was minimal (mean $+0.8 \pm 8.8 \mathrm{lbs}$ or $+0.55 \% \pm 4.9 \%$ of initial body weight), and participants visited a counselor on average once every 10 days (mean $36 \pm$ 
13 sessions). Net weight change at the end of the program (total percentage weight loss sustained after completion of both the weight loss and 12-month WLM phases) was therefore substantial (mean $-19.4 \pm 15.3 \mathrm{lbs}$ or $-11.0 \% \pm 7.4 \%$ ).

Table 2

Sample Demographics, Weight Change, and Counseling Session Attendance

\begin{tabular}{|l|c|c|}
\hline & $\underline{\text { Mean } \pm \text { SD }}$ & Range \\
\hline Gender (n= 60) (\%) & $\begin{array}{c}\text { Female: } 57(95 \%) \\
\text { Male: } 3(5 \%)\end{array}$ & $(\mathrm{n} / \mathrm{a})$ \\
\hline Age (years) & $53.2 \pm 9.7$ & $28-77$ \\
\hline Initial BMI & $28.4 \pm 4.3$ & $21-39$ \\
\hline Weight Loss (lbs) & $-20.2 \pm 14.4$ & $-56-+6$ \\
\hline $\begin{array}{l}\text { Weight Loss } \\
\text { (\% initial body wt.) }\end{array}$ & $-11.5 \% \pm 6.8 \%$ & $-30.4 \%-+4.1 \%$ \\
\hline Weight Loss Duration (d) & $179 \pm 139.8$ & $43-600$ \\
\hline $\begin{array}{l}\text { Weight Change during WLM } \\
\text { (lbs) }\end{array}$ & $+0.9 \pm 8.8$ & $-31.5-+20.3$ \\
\hline $\begin{array}{l}\text { Weight Change during WLM } \\
\text { (\% initial body wt.) }\end{array}$ & $+0.6 \% \pm 4.9 \%$ & $-16.5 \%-+8.3 \%$ \\
\hline $\begin{array}{l}\text { Net Weight Change } \\
\text { (\% initial body wt.) }\end{array}$ & $-11.0 \% \pm 7.4 \%$ & $-31.2 \%-+1.8 \%$ \\
\hline WLM Sessions & $36 \pm 13$ & $5-64$ \\
\hline
\end{tabular}

Sorting into quartiles by attendance and weight change showed wide ranges in participant outcomes, which are presented in Table 3. The majority of participants $(70 \%)$ were distributed in attendance quartiles 2 and 3 , which represent attendance patterns of once every 10 to 14 days. A similar proportion of participants (78\%) were distributed in 
quartiles 2 and 3 for weight change, representing modest weight loss or weight gain during the WLM period.

Table 3

Participant Quartile Distribution for Counseling Session Attendance and Weight Change

\begin{tabular}{|c|c|c|c|c|c|c|}
\hline & \multicolumn{4}{|c|}{ Attendance } & \multirow[b]{2}{*}{ Total } \\
\hline & & $\begin{array}{c}1 \\
(>48 \\
\text { sessions })\end{array}$ & $\begin{array}{c}2 \\
(36-47 \\
\text { sessions })\end{array}$ & $\begin{array}{c}3 \\
(20-35 \\
\text { sessions })\end{array}$ & $\begin{array}{c}\mathbf{4} \\
(<20 \\
\text { sessions })\end{array}$ & \\
\hline \multirow{4}{*}{$\begin{array}{l}\text { Weight } \\
\text { Change }\end{array}$} & $\begin{array}{c}1 \\
(\geq-5.0 \%)\end{array}$ & 1 & 2 & 2 & 0 & 5 \\
\hline & $\begin{array}{c}\mathbf{2} \\
(-0.1-4.9 \%)\end{array}$ & 4 & 8 & 4 & 2 & 18 \\
\hline & $\begin{array}{c}\mathbf{3} \\
(+0.1+4.9 \%)\end{array}$ & 5 & 9 & 12 & 3 & 29 \\
\hline & $\begin{array}{c}\mathbf{4} \\
(\geq+5.0 \%)\end{array}$ & 2 & 2 & 3 & 1 & 8 \\
\hline \multicolumn{2}{|c|}{ Total } & 12 & 21 & 21 & 6 & 60 \\
\hline
\end{tabular}

\section{Attendance and Weight Change during Maintenance}

Figure 1 plots the results from the primary comparison of counseling attendance and weight change during WLM. There was no statistically significant relationship between the total number of sessions to the counseling center and percent body weight change during WLM $(r=-.134, p=.308)$. When grouping participants into quartiles by attendance and weight change, again no statistically significant relationship was observed $\left(\chi^{2}=2.911, p=.968\right)$. 


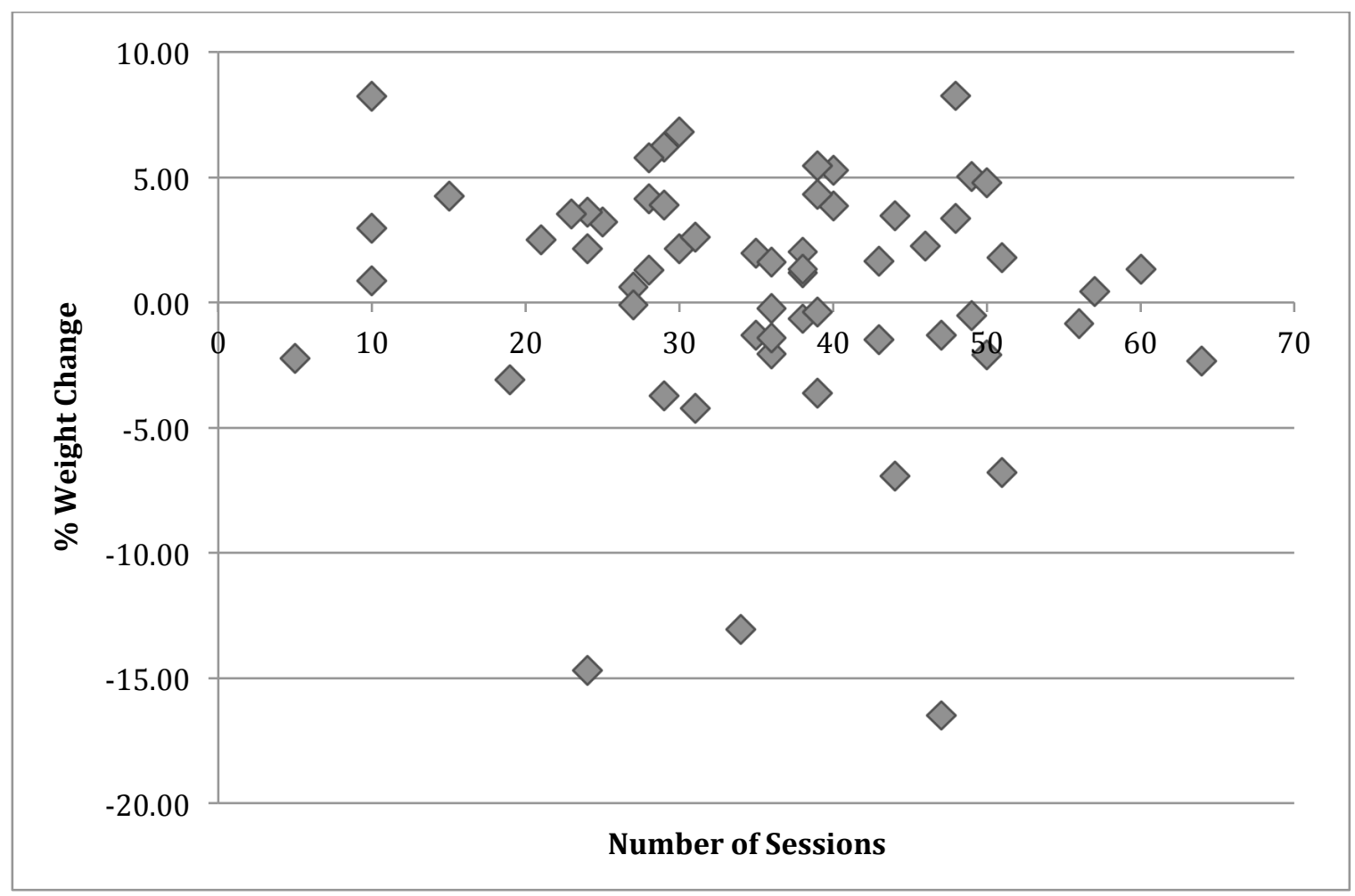

Figure 1. Percent weight change vs. number of counseling sessions attended during weight loss maintenance. No significant association was observed between how many times participants received counseling and their weight change (regain or continued loss) during the 12-month weight loss maintenance program.

\section{Secondary Analyses}

Weight loss, rate of loss, and BMI. Higher initial BMI was significantly associated with losing a greater percentage of weight prior to initiating WLM $(r=-.586$, $p<.001)$ and with significantly longer weight loss program length $(r=.414, p<.001)$. However, rate of weight loss (amount of weight lost relative to amount of time required to lose the weight) was not significantly associated with initial BMI $(r=-.064, p=.626)$.

Weight loss and weight change during weight loss maintenance. Amount of weight lost was not in itself associated with weight change during WLM $(r=-.214, p=$ .100). However, duration of weight loss program and rate of weight loss (in which a 
more negative number represents a faster rate of loss) were both weakly but positively associated with WLM weight change $(r=.312, p=.015$ and $r=.275, p=.034$, respectively), indicating that longer programs and slower weight loss were associated with greater WLM weight regain.

Long-term weight change: A second maintenance or weight loss program. Of the 60 WLM records analyzed, 15 participants opted to continue with a second 12-month WLM program contiguous to the first. Frequency of sessions during the first WLM program was not significantly associated with the decision to continue $(r=.192, p=$ .142). However, continued weight loss during WLM showed a weak, but significant, correlation with continuing for a second year $(r=-.291, p=.024)$. None of the other variables tested was associated with the likelihood of renewing WLM for a second year, nor were there any significant associations between weight change during the first WLM program and the second.

Approximately one third ( $\mathrm{n}=19)$ of participants who completed the first WLM program returned later to initiate a new round of weight loss. Four of these had also previously purchased a second WLM program. Lower goal BMI was moderately associated with greater weight loss upon return to the center $(r=-.502, p=.028)$. Having purchased a second WLM program was also moderately associated with losing more weight on the second try $(r=-.488, p=.034)$.

\section{Discussion}

The purpose of this study was to explore a possible relationship between frequency of attendance to a WLM counseling center and weight change during the first 
12 months following weight loss, for participants who completed at least 11 months of the 12-month WLM program. No significant association was observed between number of counseling sessions attended and participant weight change during WLM. However, the high attendance rate and relatively little variability in attendance observed in this sample ( $70 \%$ of participants attended on average once every $10-14$ days) limited the ability to detect a correlation between weight change and attendance, which may explain the lack of observed association. While this method of analysis allowed an effective isolation of participants' natural attendance patterns within a common timeframe, it is quite possible that participants who failed to complete the program would not exhibit such marked success with maintaining their weight. To address this issue, future research should also include non-completers in an intent-to-treat analysis, to expand the range of attendance and weight change data available for comparison.

The participants in this study represented a commonly investigated demographic group in weight management research. Their weight loss patterns, including total weight loss, rate of weight loss, and high interpersonal variability of outcomes, were also common to many other weight loss programs (Anderson et al., 2001; Johanssen, Neovius, \& Hemmingsson, 2013; Pinto et al., 2008; Svetkey et al., 2008), and the dietary and behavioral interventions applied were both effective and fairly conventional in approach. Most (87\%) participants lost a clinically significant percentage of their weight, and greater overweight was associated with longer weight loss periods and more weight lost before opting to initiate WLM; heavier people had more weight to lose before they were willing to stop losing weight, and accordingly took longer to lose that weight. Average 
weight regain during the 12 -month WLM program was minimal $(+.6 \% \pm 4.9 \%)$, well below the typical rates observed in other programs in which half or more of the lost weight might be regained within 1 year (Anderson et al., 2001; Kouvelioti et al., 2014). Furthermore, many participants $(38 \%)$ continued to lose weight during WLM, and none regained all of the weight initially lost. This, too, is a remarkable improvement over typical outcomes in long-term WLM (Svetkey et al., 2008). Therefore, these results support previous research findings that a program offering in-person counseling sessions can be highly effective to promote WLM for individuals sufficiently motivated to complete the program (Jensen et al., 2014).

It is possible that factors other than weight regain may play an important role in participant decisions to initiate contact with a WLM counselor or, alternately, that weight regain may motivate attendance for some individuals who continue to regain despite frequent sessions. The retrospective nature of this study did not allow for analysis of other possible psychosocial mediators of contact and weight change, such as being too busy, loss of interest in this particular program, motivational lapses or burnout, or whether some participants had successfully made permanent behavior changes and no longer needed frequent support. The high attrition rate and inability to follow up with participants who stopped attending the WLM center also limited the capacity to determine why attendance might cease altogether.

One unique element of this program was the ability of participants to select how often they contacted their counselor throughout the maintenance period. This paradigm was intended to provide adequate personal contact, distinct to each individual, to help 
participants develop internalized motivation and coping skills for long-term behavior change, as suggested by Teixeira et al. (2010) and Coughlin et al. (2013). However, the high attrition rate observed suggests that such an ad libitum program design may not serve the needs of participants struggling with motivation to continue their WLM efforts, who are therefore more likely to stop attending the center and drop out of the program.

One additional outcome was the finding that losing weight more slowly was associated with greater weight regain during maintenance, although total amount of lost body weight was not associated with successful WLM. Some evidence has indicated that faster initial losses tend to be associated with greater regain (Maki et al., 2007; Pinto et al., 2008); however, other studies specifically addressing the question of loss rate have suggested that faster initial losses may give individuals an advantage for overall WLM, in that they are more likely to retain an overall net deficit even if they regain a slightly higher percentage during WLM (Nackers et al., 2010). These findings may simply reflect individual metabolic or anatomical differences in the ability to lose and sustain weight; alternately, slower weight loss may be indicative of the adoption of less drastic weight management behaviors which would result in greater initial weight regain immediately following the end of the weight loss phase, but less regain over the long term beyond one year. It is also possible that those who lose weight more slowly are experiencing less motivation or greater difficulty with adherence to the weight loss plan, and so are also more likely to relapse during WLM and regain more of their weight. This possibility is supported by the outcome that greater WLM success (less regain and/or continued weight loss) in the first 12 months was associated with the pursuit of additional support. 


\section{Strengths and Limitations}

This study was novel in that it attempted to isolate contact frequency with a weight management counselor as the primary variable in WLM. Use of a commercial program, in contrast with a research program that must endeavor to treat all participants equally, allowed for the counseling services to be highly individualized, focusing on the issues most salient to the participant at any given session and adjusting counseling schedules to suit individual needs. The ad libitum, drop-in counseling format made it possible to observe the natural attendance patterns of participants to identify any associations between attendance, weight change, and additional program utilization. Furthermore, conducting such a study retrospectively prevented any unintentional bias among counselors and participants to conduct sessions more frequently than they would have otherwise.

However, this study also had several significant limitations. The relatively small sample accessed a narrow demographic range (mostly women of higher socioeconomic status who were able to afford the program) that may limit generalizability to a larger population. The retrospective design limited the ability to choose which variables should be analyzed during the course of the program, such as: duration of the sessions (e.g. brief 5 minute weigh-ins vs. 45 minutes of counseling); motivational levels and actual behavior changes occurring; specific reasons for participants' attendance patterns, such as motivation, availability, and/or perceived usefulness of the counseling support; and reasons for dropping out or for choosing to renew the WLM or weight loss programs. 


\section{Conclusions}

In the present study, results from a commercial lifestyle-based weight management program were analyzed to explore relationships between frequency of contact with a weight management counselor and long-term weight change following weight loss. Weight change over the 12-month WLM period showed average weight regain rates of less than $1 \%$ initial body weight for participants who completed the program, maintaining an average net $11 \%$ weight loss. Allowing participants to select their contact frequency may enable them to tailor the program to fit their own preferences; however, in this study absolute frequency of contact with a weight management counselor did not exhibit significant associations with WLM. Future research should therefore attempt to experimentally manipulate contact frequency to further clarify this issue. It is also possible that factors other than weight change may play a role in participants' decisions when to contact their counselor; additional research should also attempt to identify these factors to understand reasons for attrition and ensure that the available personalized counseling is both utilized and useful, to better prevent weight regain over the long term. Further investigation should also examine alternative markers of health, such as blood pressure, cholesterol, and blood glucose, which might be improved by the health behaviors employed to induce weight loss, in order to determine the extent to which modest weight regains during WLM adversely affect any initial improvements in these indicators. 


\section{References}

Anderson, J. W., Konz, E. C., Fredrich, R. C., \& Wood, C. L. (2001). Long term weight loss maintenance: A meta-analysis of US studies. American Journal of Clinical Nutrition, 74, 579-584.

Coughlin, J. W., Gullion, C. M., Brantley, P. J., Stevens, V. J., Bauck, A., Champagne, C. M. ... Appel, L. J. (2013). Behavioral mediators of treatment effects in the weight loss maintenance trial. Annals of Behavioral Medicine, 46, 369-381. doi: $10.1007 / \mathrm{s} 12160-013-9517-3$

Dale, K. S., McAuley, K. A., Taylor, R. W., Williams, S. M., Farmer, V. L., Hansen, P. ... Mann, J. I. (2009). Determining optimal approaches for weight maintenance: A randomized controlled trial. Canadian Medical Association Journal, 180, E39E46.

Desouza, C. V., Padala, P. R., Haynatzki, G., Anzures, P., Demasi, C., \& Shivaswamy, V. (2012). Role of apathy in the effectiveness of weight management programmes. Diabetes, Obesity and Metabolism, 14, 419-423.

Jensen, M. D., Ryan, D. H., Apovian, C. M., Loria, C. M., Ard, J. D., Millen, B. E.,...Tomaselli, G. F. (2014). Guidelines (2013) for the management of overweight and obesity in adults. Obesity, 22, S41-S410. doi: 10.1002/oby. 20660

Johansson, K., Neovius, M., \& Hemmingsson, E. (2013). Effects of anti-obesity drugs, diet, and exercise on weight-loss maintenance after a very-low-calorie diet or lowcalorie diet: A systematic review and meta-analysis of randomized controlled 
trials. American Journal of Clinical Nutrition, 99, 773-770. doi:

10.3945/ajen.113.070052

Kouvelioti, R., Vagenas, G., \& Langley-Evans, S. (2014). The effects of exercise and diet on weight loss maintenance in overweight and obese adults: A systematic review. Journal of Sports Medicine and Fitness. Advance online publication. Retrieved from http://www.minervamedica.it

Maki, K. C., Rains, T. M., Kaden, V. N., Raneri, K. R., \& Davidson, M. H. (2007). Effects of a reduced-glycemic-load diet on body weight, body composition, and cardiovascular disease risk markers in overweight and obese adults. American Journal of Clinical Nutrition, 85, 724-34.

Nackers, L. M., Ross, K. M., \& Perri, M. G. (2010). The association between rate of initial weight loss and long-term success in obesity treatment: Does slow and steady in the race? International Journal of Behavioral Medicine, 17, 161-167. doi: $10.1007 / \mathrm{s} 12529-010-9092-\mathrm{y}$

Nguyen, B., Shrewsbury, V.A., O'Connor, J., Steinbeck, K. S., Hill, A. J., Shah, S., ... Baur, L. A. (2013). Two-year outcomes of an adjunctive telephone coaching and electronic contact intervention for adolescent weight-loss maintenance: The Loozit randomized controlled trial. International Journal of Obesity, 37, 468472. doi: $10.1038 /$ ijo. 2012.74

Orleans, C. T. (2000). Promoting the maintenance of health behavior change: Recommendations for the next generation of research and practice. Health Psychology, 19, S76-83. doi: 10.1037/0278.6133.19.1(Supp1.).76 
Perri, M. G., Limacher, M. C., Castel-Roberts, K., Daniels, M. J., Durning, P. E., \& Janicke, D. M. (2014). Comparative effectiveness of three doses of weight-loss counseling: Two-year findings from the rural LITE trial. Obesity, 22. Advance publication, retrieved from http://www.researchgate.net. doi: 10.1002/oby.20832

Perri, M. G., Limacher, M. C., Castel-Roberts, K., Daniels, M. J., Durning, P. E., \& Janicke, D. M., ... Martin, A. D. (2014). Comparative effectiveness of three doses of weight-loss counseling: Two-year findings from the rural LITE trial. Obesity, 22. Advance publication, retrieved from http://www.researchgate.net. doi: $10.1002 /$ oby.20832

Perri, M. G., Limacher, M. C., Durning, P. E., Janicke, D. M., Lutes, L. D., Bobroff, L. B., ... Martin, A. D. (2008). Treatment of obesity in underserved rural settings (TOURS): A randomized trial of extended-care programs for weight management. Archives of Internal Medicine, 168, 2347-2354. doi:

10.1001/archinte.168.21.2347

Pinto, A. M., Gorin, A. A., Raynor, H. A., Tate, D. F., Fava, J. L., \& Wing, R. R. (2008). Successful weight loss maintenance in relation to method of weight loss. Obesity (Silver Spring), 16, 2456-2461. doi: 10.1013/oby.2008.364

Powell, L. H., Calvin, J. E., III, \& Calvin., J. E., Jr. (2007). Effective obesity treatments. American Psychologist, 62, 234-246. doi: 10.1037/0003-066X.62.3.234

Sherwood, N. E., Crain, A. L., Martinson, B. C., Anderson, C. P., Hayes, M. G., Anderson, J. D., ... Jeffery, R. W. (2013). Enhancing long-term weight loss 
maintenance: 2 year results from the Keep It Off randomized controlled trial. Preventative Medicine, 56, 171-177. doi: 10.1016/j.ypmed.2012.12.014

Svetkey, L. P., Stevens, V. J., Brantley, P. J., Appel, L. J., Hollis, J. F., Loria, C. M., ... Aicher, K. (2008). Comparison of strategies for sustaining weight loss: The weight loss maintenance randomized controlled trial. Journal of the American Medical Association, 299, 1139-1147.

Teixeira, P. J., Silva, M. N., Mata, J., Palmeira, A. L., \& Markland, D. (2012). Motivation, self-determination, and long-term weight control. International Journal of Behavioral Nutrition and Physical Activity, 9(22). Retrieved from: http://www.ijbnpa.org/content/9/1/22

Thomas, J. G., \& Wing, R. R. (2009). Maintenance of long-term weight loss. Rhode Island Medicine \& Health, 92, 53-57.

U.S. Centers for Disease Control and Prevention, National Center for Health Statistics. (2013). FastStats: Obesity and Overweight. Retrieved from http://www.cdc.gov/nchs/fastats/obesity-overweight.htm

Wing, R. R., \& Phelan, S. (2005). Long-term weight loss maintenance. American Journal of Clinical Nutrition, 82S, 222S-225S.

Wing, R. R., Tate, D. F., Gorin, A. A., Raynor, H. A., \& Fava, J. L. (2006). A selfregulation program for maintenance of weight loss. New England Journal of Medicine, 355, 1563-1571. 
CHAPTER 3

SUMMARY AND RECOMMENDATIONS 


\section{Summary}

Rising obesity trends in the U.S. are strongly associated with increased risk for chronic disease. Modest 3-5\% weight loss can improve health outcomes, although the standard "clinically significant" goal remains at 5-10\% of initial body weight (Jensen et

al., 2014). Unfortunately, in the fight to combat adult obesity, losing weight is only half the battle. Many successful weight loss methods have been identified for motivated individuals; however, the greater difficulty lies in sustaining weight loss long term. Research has now identified the behaviors and attitudes most conducive to long term weight loss maintenance (WLM), though some unresolved issues remain regarding how to best convey this information in a manner that helps individuals struggling with WLM to develop these behaviors and attitudes into permanently ingrained lifestyle changes.

The most effective WLM outcomes are typically seen with individualized, inperson counseling provided on an ongoing basis. However, even within these types of programs significant weight regain is common, and the reasons for this remain unknown. One aspect of program design that had not been previously explored in WLM literature was the element of contact frequency: how often participants receive support from their counselors, and whether participants should have any influence over when they receive the support. The current study explored contact frequency in WLM by investigating the outcomes of a commercial weight management program in which participants, not counselors, set the schedule for their WLM counseling sessions. In this 12-month program, weekly counseling sessions were encouraged, but all sessions were held on an entirely drop-in basis dependent upon the participant's desires and availability. 
For some participants, this ad libitum contact schedule appeared to be beneficial, as weight regain rates for those who completed the program were much improved over conventional, pre-scheduled programs. However, no association was found between frequency of contact and weight changes during the 12-month WLM period. The high attrition rate, high frequency and narrow variability of attendance rates, and small sample size of program completers limited the power of this study to identify significant outcomes; however, it is also possible that the primary reasons for an individual's attendance pattern lie beyond absolute weight change on the scale. The retrospective design of this study limited the ability to probe more deeply into the motivations, life experiences, and other mediating factors that determine whether and how often participants seek support in the first 12 months following weight loss.

\section{Recommendations}

Given the scarcity of research on this topic, additional investigation into contact schedules and participant utilization of supportive counseling is warranted. Several particular elements might be considered for future research. The first is whether flexible, at-will contact schedules (e.g. "anytime this week") might be superior to pre-scheduled regular appointments (e.g. "every second Thursday at $2 \mathrm{pm}$ ) for participant retention throughout a program, attendance at the appointments, and maintenance of weight-related behavior change; this option might be particularly important for participants suffering from burnout or lack of motivation, but less important for those whose behaviors are more stabilized and therefore require less support. The second consideration needing exploration is the provision of contingent care: the availability of more frequent support 
beyond the regular contact schedule, which the participant can seek during periods of relapse or when motivation is waning.

Additional research is also needed to explore the motivations, desires, and other psychosocial elements of participants throughout the course of a WLM program. Only $30 \%$ of initial purchasers of the WLM program in this study attended at least 11 months of the 12-month program, indicating that many start out with good intentions but few persevere to the end. A more thorough understanding of why participants drop out or utilize the counseling services only sporadically would be highly useful to reduce attrition among participants who need the ongoing support to sustain their weight-related health behaviors, and ensure that all people working to maintain their weight and improve their health receive adequate and appropriate support in their endeavors.

Finally, a greater understanding of the links between health behavior change, weight loss/WLM outcomes, and physiological markers of health (such as blood pressure, cholesterol, and blood glucose) is also important. While weight loss is often associated with improved health outcomes, losing weight is no absolute guarantee of improved health. However, the physiological consequences of improving one's diet and becoming more physically active to induce weight loss could produce positive health changes that might not be impaired by subsequent modest weight regain, provided the health behaviors themselves are essentially sustained. Research to further clarify the connection between weight loss, weight regain, and physiological markers of health has the potential to redefine "weight management success" in terms of more meaningful outcomes than a single number on the scale. 


\section{References}

Academy of Nutrition and Dietetics. (2013). Which nutrition services are covered? Retrieved from http://www.eatright.org/HealthProfessionals/ content.aspx?id=8175

American Dietetic Association. (2008). Position of the American Dietetic Association: Weight management. doi: 10.1016/j.jada.2008.11.041

Anderson, J. W., Konz, E. C., Fredrich, R. C., \& Wood, C. L. (2001). Long term weight loss maintenance: A meta-analysis of US studies. American Journal of Clinical Nutrition, 74, 579-584.

Anderson, J. W., Vichitbandra, S., Qian, W., \& Kryscio, R. J. (1999). Long term weight maintenance after intensive weight loss program. Journal of the American College of Nutrition, 18, 620-627.

Ashley, J. M., St. Jeor, S. T., Perumean-Chaney, S., Schrage, J., \& Bovee, V. (2001). Meal replacements in weight intervention. Obesity Research, 9[Supplement], 312S-320S.

Brantley, P. J., Appel, L. J., Hollis, J., Stevens, V. J., Ard, J., Champagne, C. M., ... Svetkey, L. P. (2008). Weight loss maintenance (WLM): Design and rationale of a multi-center trial to sustain weight loss. Clinical Trials, 5, 546-556. doi: $10.1177 / 1749774508096315$

Brunerova, L., Smejkalova, V., Potockova, J., \& Andel, M. (2007). A comparison of the influence of a high-fat diet enriched in monounsaturated fatty acids and conventional diet on weight loss and metabolic parameters in obese non-diabetic and Type 2 diabetic patients. Diabetic Medicine, 24, 533-540. doi: 10.1111/j.1464-5491.2007.02104.x

Centers for Disease Control and Prevention, National Center for Health Statistics. (2013). FastStats: Obesity and Overweight. Retrieved from http://www.cdc.gov/nchs/fastats/obesity-overweight.htm

Centers for Disease Control and Prevention, Division of Nutrition, Physical Activity, and Obesity. (2014a). Healthy Weight: About BMI for Adults. Retrieved from http://www.cdc.gov/healthyweight/index.html

Centers for Disease Control and Prevention, Division of Nutrition, Physical Activity, and Obesity. (2014b). Overweight and obesity: Adult obesity facts. Retrieved from http://www.cdc.gov/obesity/data/adult.html 
Cho, J. H., Jae, S. Y., Choo, I. H., \& Choo, J. (2014). Health-promoting behavior among women with abdominal obesity: A conceptual link to social support and perceived stress. Journal of Advanced Nursing, 70, 1381-90. doi: 10.1111/jan.12300

Coughlin, J. W., Gullion, C. M., Brantley, P. J., Stevens, V. J., Bauck, A., Champagne, C. M. ... Appel, L. J. (2013). Behavioral mediators of treatment effects in the weight loss maintenance trial. Annals of Behavioral Medicine, 46, 369-381. doi: $10.1007 / \mathrm{s} 12160-013-9517-3$

Dale, K. S., McAuley, K. A., Taylor, R. W., Williams, S. M., Farmer, V. L., Hansen, P. ... Mann, J. I. (2009). Determining optimal approaches for weight maintenance: A randomized controlled trial. Canadian Medical Association Journal, 180, E39E46.

de Mutsert, R., Sun, Q., Willett, W. C., Hu, F. B., \& van Dam, R. M. (2014). Overweight in early adulthood, adult weight change, and risk of type 2 diabetes, cardiovascular diseases, and certain cancers in men: A cohort study. American Journal of Epidemiology, 179, 1353-1365. doi: 10.1093/aje/kwu052

Desouza, C. V., Padala, P. R., Haynatzki, G., Anzures, P., Demasi, C., \& Shivaswamy, V. (2012). Role of apathy in the effectiveness of weight management programmes. Diabetes, Obesity and Metabolism, 14, 419-423.

Ebbeling, C. B., Swain, J. F., Feldman, H. A., Wong, W. W., Hachey, D. L., GarciaLago, E., \& Ludwig, D. S. (2012). Effects of dietary composition during weight loss maintenance: A controlled feeding study. Journal of the American Medical Association, 307, 2627-2634. doi: 10.1001/jama.2012.6607

Greenwood, J. L. J. (2009). The complexity of weight loss counseling: Commentary on Phelan, Nallari, Darroch \& Wing's "What do physicians recommend to their overweight and obese patients?" [Peer commentary by J. L. J. Greenwood], Journal of the American Board of Family Medicine, 22, 113-114. doi: 10.3122/jabfm.2009.02.080256

Jensen, M. D., Ryan, D. H., Apovian, C. M., Loria, C. M., Ard, J. D., Millen, B. E.,...Tomaselli, G. F. (2014). Guidelines (2013) for the management of overweight and obesity in adults. Obesity, 22, S41-S410. doi: 10.1002/oby.20660

Johansson, K., Neovius, M., \& Hemmingsson, E. (2013). Effects of anti-obesity drugs, diet, and exercise on weight-loss maintenance after a very-low-calorie diet or lowcalorie diet: A systematic review and meta-analysis of randomized controlled trials. American Journal of Clinical Nutrition, 99, 773-770. doi: 10.3945/ajcn.113.070052 
Klem, M. L., Wing, R. R., McGuire, M. T., Seagle, H. M., \& Hill, J. O. (1997). A descriptive study of individuals successful at long-term maintenance of substantial weight loss. American Journal of Clinical Nutrition, 66, 239-246.

Kouvelioti, R., Vagenas, G., \& Langley-Evans, S. (2014). The effects of exercise and diet on weight loss maintenance in overweight and obese adults: A systematic review. Journal of Sports Medicine and Fitness. Advance online publication. Retrieved from http://www.minervamedica.it

Kraschnewski, J. L., Sciamanna, C. N., Stuckey, H. L., Chuang, C. H., Lehman, E. B., Hwang, K. O., ...Nembhard, H. B. (2013). A silent response to the obesity epidemic: Decline in US physician weight counseling. Medical Care, 51, 186192. doi: 10.1097/MLR.0b013e3182726c33

Maki, K. C., Rains, T. M., Kaden, V. N., Raneri, K. R., \& Davidson, M. H. (2007). Effects of a reduced-glycemic-load diet on body weight, body composition, and cardiovascular disease risk markers in overweight and obese adults. American Journal of Clinical Nutrition, 85, 724-34.

Myers, V. H., McVay, M. A., Champagne, C. M., Hollis, J. F., Coughlin, J. W., Funk, K. L., ... Brantley, P. J. (2013). Weight loss history as a predictor of weight loss: Results from Phase I of the weight loss maintenance trial. Journal of Behavioral Medicine, 36, 574-582. doi: 10.1007/s10865-012-9450-0

Nackers, L. M., Ross, K. M., \& Perri, M. G. (2010). The association between rate of initial weight loss and long-term success in obesity treatment: Does slow and steady in the race? International Journal of Behavioral Medicine, 17, 161-167. doi: 10.1007/s12529-010-9092-y

National Weight Control Registry. (n.d.). The National Weight Control Registry. http://www.nwcr.ws/

Nawaz, H., \& Katz, D. (2001). American College of Preventive Medicine practice policy statement: Weight management counseling of overweight adults. American Journal of Preventive Medicine, 21, 73-78. doi: 10.1016/S07493797(01)00317-8

Nguyen, B., Shrewsbury, V.A., O'Connor, J., Steinbeck, K. S., Hill, A. J., Shah, S., ... Baur, L. A. (2013). Two-year outcomes of an adjunctive telephone coaching and electronic contact intervention for adolescent weight-loss maintenance: The Loozit randomized controlled trial. International Journal of Obesity, 37, 468472. doi: $10.1038 /$ ijo.2012.74 
Orleans, C. T. (2000). Promoting the maintenance of health behavior change: Recommendations for the next generation of research and practice. Health Psychology, 19, S76-83. doi: 10.1037/0278.6133.19.1(Suppl.).76

Perri, M. G. (2014). Effects of behavioral treatment on long-term weight loss: Lessons learned from the Look AHEAD trial. Obesity, 22, 3-5. doi: 10.1002/oby.20672

Perri, M. G., Limacher, M. C., Castel-Roberts, K., Daniels, M. J., Durning, P. E., \& Janicke, D. M., ... Martin, A. D. (2014). Comparative effectiveness of three doses of weight-loss counseling: Two-year findings from the rural LITE trial. Obesity, 22. Advance publication, retrieved from http://www.researchgate.net. doi: $10.1002 /$ oby. 20832

Perri, M. G., Limacher, M. C., Durning, P. E., Janicke, D. M., Lutes, L. D., Bobroff, L. B., ... Martin, A. D. (2008). Treatment of obesity in underserved rural settings (TOURS): A randomized trial of extended-care programs for weight management. Archives of Internal Medicine, 168, 2347-2354. doi: 10.1001/archinte.168.21.2347

Pinto, A. M., Gorin, A. A., Raynor, H. A., Tate, D. F., Fava, J. L., \& Wing, R. R. (2008). Successful weight loss maintenance in relation to method of weight loss. Obesity (Silver Spring), 16, 2456-2461. doi: 10.1013/oby.2008.364

Powell, L. H., Calvin, J. E., III, \& Calvin., J. E., Jr. (2007). Effective obesity treatments. American Psychologist, 62, 234-246. doi: 10.1037/0003-066X.62.3.234

Radcliff, T. A., Bobroff, L. B., Lutes, L. D., Durning, P. E., Daniels, M. J., Limacher, M. C., ... Perri, M. G. (2012). Comparing costs of telephone versus face-to-face extended care programs for the management of obesity in rural settings. Journal of the Academy of Nutrition and Dietetics, 112, 1363-1373. doi: 10.1016/j.jand.2012.05.002

Sherwood, N. E., Crain, A. L., Martinson, B. C., Anderson, C. P., Hayes, M. G., Anderson, J. D., ... Jeffery, R. W. (2013). Enhancing long-term weight loss maintenance: 2 year results from the Keep It Off randomized controlled trial. Preventative Medicine, 56, 171-177. doi: 10.1016/j.ypmed.2012.12.014

Sherwood, N. E., Crain, A. L., Martinson, B. C., Hayes, M. G., Anderson, J. D., Clausen, J. M., ...Jeffery, R. W. (2011). Keep It Off: A phone-based intervention for long-term weight-loss maintenance. Contemporary Clinical Trials, 32, 551-560. doi: $10.1016 /$ j.cct.2011.03.011

Svetkey, L. P., Stevens, V. J., Brantley, P. J., Appel, L. J., Hollis, J. F., Loria, C. M., ... Aicher, K. (2008). Comparison of strategies for sustaining weight loss: The 
weight loss maintenance randomized controlled trial. Journal of the American Medical Association, 299, 1139-1147.

Sweeney, T. E., \& Morton, J. M. (2013). The human gut microbiome: a review of the effect of obesity and surgically induced weight loss. Journal of the American Medical Association - Surgery, 148, 563-569. doi: 0.1001/jamasurg.2013.5

Tang, J., Abraham, C., Greaves, C., \& Yates, T. (2014). Self-directed interventions to promote weight loss: A systematic review of reviews. Journal of Medical Internet Research, 16, e58. doi: 10.2196/jmir.2857

Teixeira, P. J., Silva, M. N., Mata, J., Palmeira, A. L., \& Markland, D. (2012). Motivation, self-determination, and long-term weight control. International Journal of Behavioral Nutrition and Physical Activity, 9(22). Retrieved from: http://www.ijbnpa.org/content/9/1/22

Thomas, D., Vydelingum, V., \& Lawrence, J. (2010). E-mail contact as an effective strategy in the maintenance of weight loss in adults. Journal of Human Nutrition and Diet, 24, 32-38. doi: 10.1111/j.1365-277x.2010.01123.x

Thomas, J. G., \& Wing, R. R. (2009). Maintenance of long-term weight loss. Rhode Island Medicine \& Health, 92, 53-57.

United Healthcare. (2014). Member benefits and coverage. Retrieved from http://www.myuhc.com/member/benefitandcoverage

Wing, R. R., \& Phelan, S. (2005). Long-term weight loss maintenance. American Journal of Clinical Nutrition, 82s, 222S-225S.

Wing, R. R., Tate, D. F., Gorin, A. A., Raynor, H. A., \& Fava, J. L. (2006). A selfregulation program for maintenance of weight loss. New England Journal of Medicine, 355, 1563-1571. 
APPENDIXES 


\section{APPENDIX A: Letters of Consent from Participating Facilities}

To: Ashlee Gossard

855 Bing Dr. \#1

Santa Clara, CA 95051

LFL Facility: Lite For Life of Menlo Park, 713 Oak Grove Ave. Menlo Park, CA 94025

Contact Person: Linda Hicks, Owner

Re: Master's Thesis project for Ashlee Gossard - working title: "Frequency of Counselor Visits and Successful Weight Maintenance following Weight Loss"

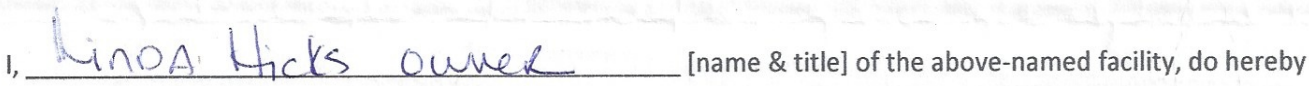
give my consent to participate in the research project listed above, and certify that I have the appropriate authority to provide this consent. I agree that the student, Ashlee Gossard, will be provided access to the files of clients who have completed the Life For Life (LFL) weight maintenance program ("Maintenance") at my facility for the purposes of developing a dataset for analysis in her project. The dataset to be developed may include information such as: client height, age, and gender; starting weight, ending weight, and time taken to lose that weight on the Reducing program; goal weight for Maintenance; start- and end-dates of Maintenance program, dates and frequency of check-ins/weigh-ins, and client weight at each check in. Other data may be recorded as available, and all data entered will be completely deidentified, meaning that no names, addresses, phone numbers, emails, other contact information, or other identifying information of any kind will be attached to each record in the data set; only completed programs will be entered and analyzed, using no data from current (in progress) Maintenance programs.

Upon the completion of this research project (tentatively by 12/31/2014), I will be provided with a summary report of the findings of this research.

I understand and agree to the above conditions, and have retained one copy of this informed consent for my records.

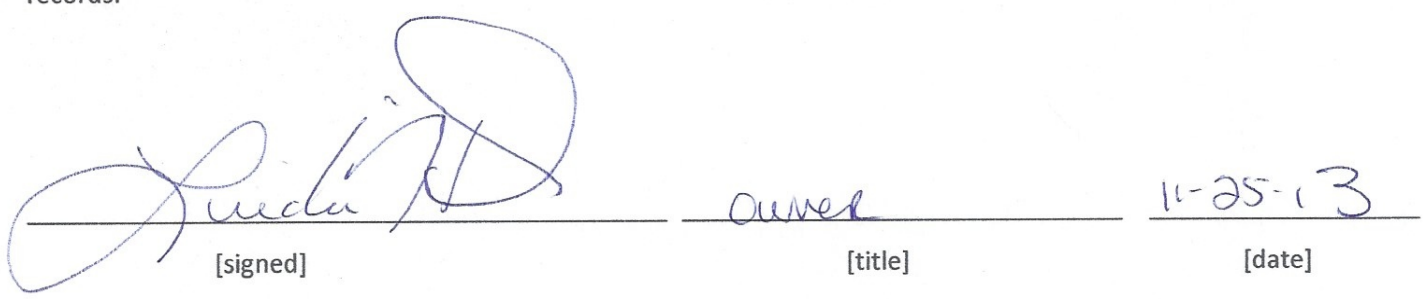


To: Ashlee Gossard

855 Bing Dr. \#1

Santa Clara, CA 95051

LFL Facility: Lite For Life of San Carlos, 1101 Laurel St. San Carlos, CA 94070

Contact Person: Jennifer Lesyna, Owner

Re: Master's Thesis project for Ashlee Gossard - working title: "Frequency of Counselor Visits and Successful Weight Maintenance following Weight Loss"

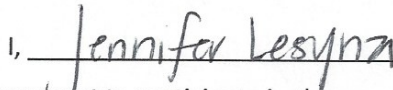
[name \& title] of the above-named facility, do hereby give my consent to participate in the research project listed above, and certify that I have the appropriate authority to provide this consent. I agree that the student, Ashlee Gossard, will be provided access to the files of clients who have completed the Life For Life (LFL) weight maintenance program ("Maintenance") at my facility for the purposes of developing a dataset for analysis in her project. The dataset to be developed may include information such as: client height, age, and gender; starting weight, ending weight, and time taken to lose that weight on the Reducing program; goal weight for Maintenance; start- and end-dates of Maintenance program, dates and frequency of check-ins/weigh-ins, and client weight at each check in. Other data may be recorded as available, and all data entered will be completely deidentified, meaning that no names, addresses, phone numbers, emails, other contact information, or other identifying information of any kind will be attached to each record in the data set; only completed programs will be entered and analyzed, using no data from current (in progress) Maintenance programs.

Upon the completion of this research project (tentatively by $12 / 31 / 2014$ ), I will be provided with a summary report of the findings of this research.

I understand and agree to the above conditions, and have retained one copy of this informed consent for my records.

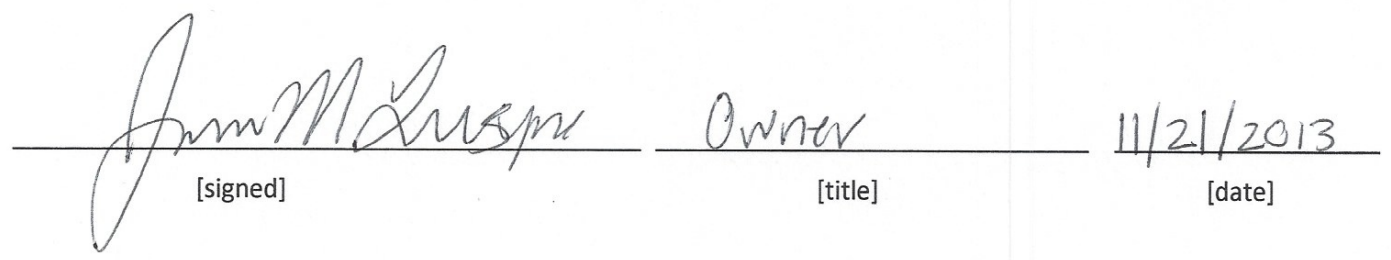




\section{APPENDIX B: IRB Approval}

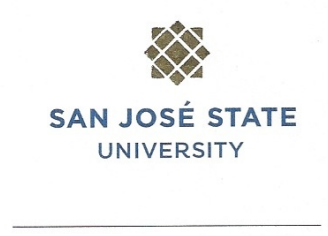

Division of Academic Affairs

Associate Vice President Graduate Studies \& Research

www.sjsu.edu/gradstudies

One Washington Square San José, California 95192-0025 Voice: 408-924-2427

www.sjsu.edu
To: Ashlee Gossard

From: Pamela Stacks, Ph.D. Associate Vice President

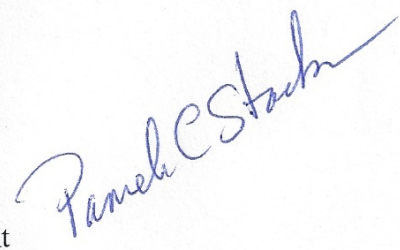

Graduate Studies and Research

Date: March 11, 2014

The Human Subjects-Institutional Review Board has registered your study entitled:

"Relationship between Frequency of Visits to a Drop-in Weight Management Clinic and Successful weight Maintenance Following Weight Loss"

This registration, which provides exempt status under Exemption Category 4 of SJSU Policy S08-7, is contingent upon the subjects included in your research project being appropriately protected from risk. Specifically, protection of the anonymity of the subjects' identity with regard to all data that may be collected about the subjects from your secondary sources needs to be ensured.

This registration includes continued monitoring of your research by the Board to assure that the subjects are being adequately and properly protected from such risks. If at any time a subject becomes injured or complains of injury, you must notify Dr. Pamela Stacks, Ph.D. immediately. Injury includes but is not limited to bodily harm, psychological trauma, and release of potentially damaging personal information. This approval for the human subject's portion of your project is in effect for one year, and data collection beyond March 11, 2015 requires an extension request.

If you have any questions, please contact me at (408) 924-2427.

Protocol \#: S1402040

cc. Clarie Hollenbeck 0058
The California State University
Chancellor's Office Bakersfield, Channel Islands, Chico, Dominguez Hills Los Angeles, Meritime Academy Mentererg Bay Northridge, Pomona, Sacramento, San Bernardino,
San Diegge, San Francisco, San José, San Luis Obispo,
San 